\title{
Etching Depthvariation of Brass Material for Different Operating Conditions
}

\author{
Jadhav Saurabh M., Karatkar Onkar V., Bangale Kamesh N., Choudhari Deepak B., \\ Abhay A. Utpat, Kamble Banduraj K.
}

\begin{abstract}
The conventional machining deals with the removal of metal by direct contact between the tool and the work piece, which results into the formation of chips, debris etc. So, there is scope for unconventional machining process like PCM. This paper focuses on study of Depth of etching in photochemical machining by varying temperature and time of etching. The objective is to study the effect of these parameters and find relation between them. This process is the bridge between $2 \mathrm{D}$ and 3D manufacturing processes. Initially the photo-tools are prepared; Brass material was taken for experimentation. The control parameters were temperature, concentration and time. The concentration of etchant $\left(\mathrm{FeCl}_{3}\right)$ was 781 grams per liter. The temperature and time are varying parameters for etching. The readings are taken by Digital Micro-meter. A pattern may be transferred onto a photoresist film by exposing the photoresist to light through a mask of the pattern called photo-tool and obtain pattern on metal.
\end{abstract}

Index Terms-Photo Chemical Machining, Photo tool, etching, Brass material.

\section{INTRODUCTION}

Photochemical machining (PCM), also known as photochemical milling or photo etching, is a chemical milling process used to fabricate sheet metal components using a photoresist and etchants to corrosively machine away selected areas [1]. The tooling is inexpensive and quickly produced.

\section{Process:}

The process starts by printing the shape of the part onto optically clear and dimensionally stable photographic film, called "photo-tool"[2]. Then the metal sheets are cut to size, cleaned and then photoresist is uniformly applied on it. Photoresist is dry and make ready for UV light. Photo-tool is laminated over sheet metal and sheet metal is placed in UV light expose. After exposing of UV light sheet metal is dip into the developer. Now sheet metal is dip into the etchant (commonly ferric chloride $\left[\mathrm{FecCl}_{3}\right]$ etchant).Then lastly photoresist is removed by etchant and we get the required product[3].

Jadhav Sourabh M., Mechanical Department, SVERI's COE, Pandharpur, India

Karatkar Onkar V., Mechanical Department, SVERI's COE, Pandharpur, India

Bangalekamesh N., Mechanical Department, SVERI's COE, Pandharpur,India

Choudhari Deepak B., Mechanical Department, SVERI's COE, Pandharpur,India

Utpat Abhay A., Professor, Mechanical Engineering Department, SVERI's COE, Pandharpur,India

Kamble Bandurak K.., PG Student, Mechanical Department, SVERI's $\mathrm{COE}$, Pandharpur,India,
Ferric chloride $(\mathrm{FeCl} 3)$ is the most commonly used etchant for photochemical machining (PCM) .In an ideal world, to maintain a constant rate of etching and hence control of part dimensions dependent on etch time, the etchant composition would be constant[4]. Unfortunately, in the real world, the etchant composition changes continuously. As an n-valent metal is dissolved into solution, etchant is consumed and the by-products of ferrous chloride $(\mathrm{FeCl} 3)$ and metal chlorides are generated [5].

The findings showed that more than half of the PCM companies used regeneration of ferric chloride etchant and $76.3 \%$ of companies were prepared to use a more environment-friendly regeneration system at a higher overall cost[1]. The findings of this study and the analysis carried out can be used by PCM companies.In negative photoresist part which is dark in photo-tool is removed and remaining part of photo-tool become hard and in positive photoresist inversely like negative photoresist the part which is dark is remain hard and other part will become softer and that non harden part is removed.Today the cost micro machining is expensive than macro machining. PCM offers economical and alternative way of other costlier processes like laser cutting. This method is relatively new [6]. Though it is economical but relatively less popular process in the field of manufacturing. Owing to the development of micro fluidics and micro system technology over last 20 years, PCM has received greater attention [7]. Most commonly used materials in the field of photochemical machining are copper, brass, stainless steel. The major applications of this process are in the field of aerospace, biomedical, electronic parts and decorative items. The microfabrication of components like microchannels using PCM has also been reported by few researchers [8-12].

\section{METHODOLOGY}

\subsection{Material selection: -}

The Brass is the material used for this study, because it is more elastic after gold and aluminum. The size of specimen used is $30 \mathrm{~mm} \times 30 \mathrm{~mm} \times 0.740 \mathrm{~mm}(\mathrm{~W} \times \mathrm{L} \times \mathrm{T})$.

Photoresist chemical is blue coating ink. Developer $\mathrm{NaOHsolution}$ and etchant of $\mathrm{FeCl}_{3}$ with concentration $781 \mathrm{~g} / 1$. 


\subsection{Experimental procedure: -}

The experimental procedure is presented in Fig. 1

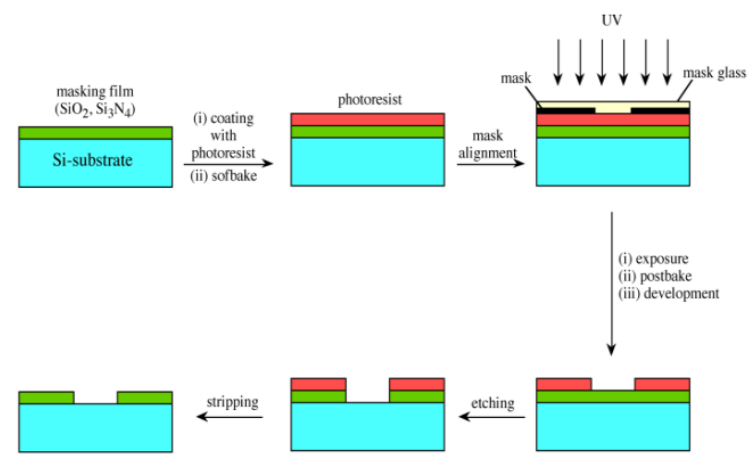

Fig.1 Basic procedure of the photochemical machining process

\section{Creation of Photo tool: -}

Photochemical machining process is carried out by using a photo tool. The photo tool is an AutoCAD drawing with detailed dimensions of the required shape which is then printed on a tress paper or transparent paper.

\section{Preparation of workpiece: -}

After preparing the photo tool the Brass material is cut into required size. The first task is to clean the work piece. The cleaning of the surface is done firstly by polishing the surface with a sand paper and then cleaning it by thinner (trichloroethylene or acetone). This step is done to make the surface of workpiece free from foreign particles, debris, dust, grease, oil and other contaminants. Because of polishing and cleaning with thinner it gets easier to have a good adhesion of photoresist with the metal surface.

\section{Coating of workpiece: -}

After cleaning the workpiece, a thin layer of photoresist is applied on the metal surface. There are two types of photoresist viz. positive photoresist and negative photoresist. For this study negative photoresist has taken. The characteristic of negative photoresist is that it hardens the area of metal from where the light is passed.

\section{UV Exposure: -}

The generated photo tool is put on the coated work pieceand exposed to UV source for 60 seconds. The UV light used has the lamp of $1 \mathrm{KW}$ light. The setup for UV exposure is as shown in fig 2.

Development Phase: - After UV exposure the specimen is held in the developer $(\mathrm{NaOH})$ for 120 seconds, which results in the formation of impression on work piece with good etching results. After that specimen, is washed with water.

\section{Etching: -}

The final step of the machining is to put the developed metal workpiece into the etchant. The pressure of pump used for etchant spray is $0.5 \mathrm{~kg} / \mathrm{cm}^{2}$. The etchant is the solution of $\mathrm{FeCl}_{3}$ and water. The concentration of the etchant is 781 grams per liter and temperature of etchant is varying $\left(34-42^{\circ} \mathrm{C}\right)$. Etching is carried out for different time period $(2-8$ min.). At the end the specimen is cleaned by water and dried. The readings are taken by digital micro-meter.

\section{UV Exposure Machine}
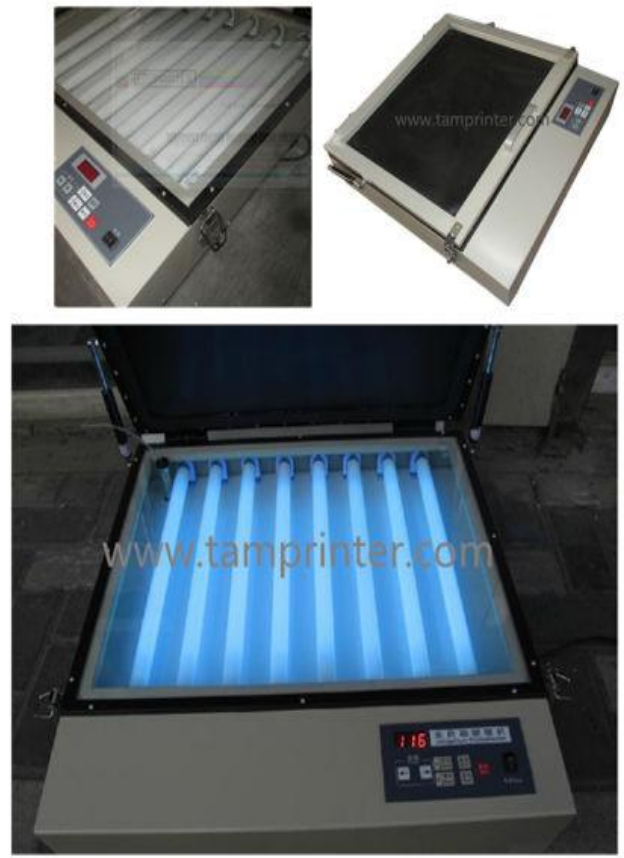

Fig 2. UV light source

\subsection{Fixed Parameters}

Material of plate: Brass

Thickness ofplate: $0.740 \mathrm{~mm}$

UV Light Expose Time: $60 \mathrm{sec}$.

Developing Time: $120 \mathrm{Sec}$.

Thickness of photoresist: $0.045 \mathrm{~mm}$

\section{Results AND Discussion}

After studying the process of photochemical machining by using varying etching parameters, the results for different readings were obtained and are presented in Table 1.

Table 1. Experimental readings for depth of etch

\begin{tabular}{|c|c|c|}
\hline Temperature $\left({ }^{\circ} \mathrm{C}\right)$ & $\begin{array}{c}\text { Depth of Etched } \\
\text { Component }(\mathrm{mm})\end{array}$ & Time(min.) \\
\hline \multirow{4}{*}{34} & 0.013 & 2 \\
\cline { 2 - 3 } & 0.022 & 4 \\
\cline { 2 - 3 } & 0.034 & 6 \\
\hline \multirow{4}{*}{38} & 0.060 & 8 \\
\cline { 2 - 3 } & 0.056 & 2 \\
\cline { 2 - 3 } & 0.071 & 4 \\
\cline { 2 - 3 } & 0.088 & 6 \\
\hline \multirow{4}{*}{42} & 0.105 & 8 \\
\hline & 0.178 & 4 \\
\cline { 2 - 3 } & 0.218 & 6 \\
\cline { 2 - 3 } & 0.262 & 8 \\
\hline
\end{tabular}




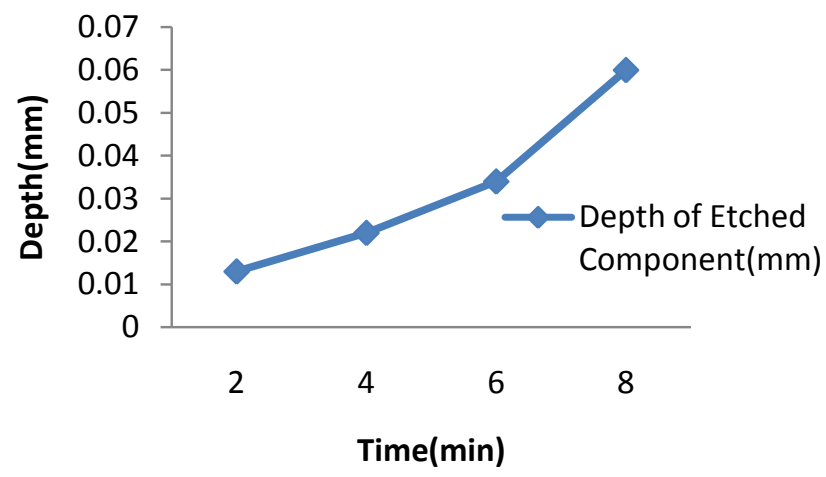

Fig.3.Etching Temperature- $34^{\circ} \mathrm{C}$

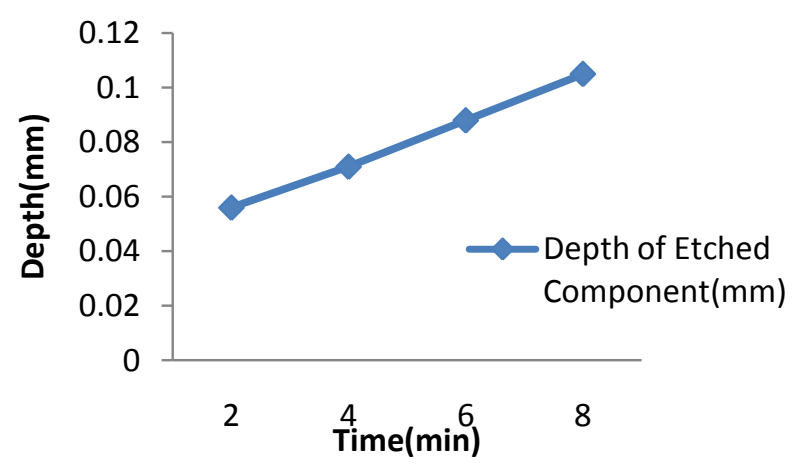

Fig.4.Etching Temperature- $38^{\circ} \mathrm{C}$

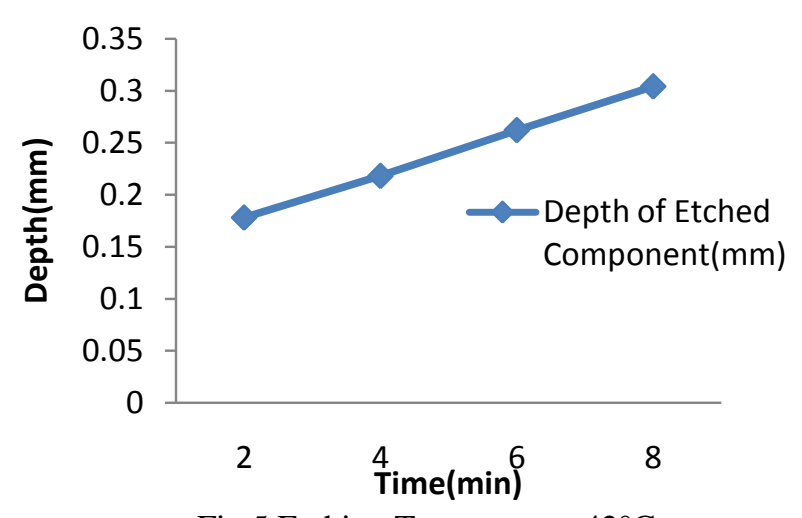

Fig.5.Etching Temperature- $42^{\circ} \mathrm{C}$

Fig. 3, 4, and 5 shows variation of etching depth with time for different temperatures. As the temperature increases from $34^{\circ} \mathrm{C}$ to $42^{\circ} \mathrm{C}$ etching depth increases accordingly.

$>$ The negative photoresiist is used and UV light passes through the coloured photo tool, so the portion becomes hard from where maximum amount of light is passed and portion remains soft from where passing of light is less.

$>$ Above charts shows the different depth of etching for different temperatures and time.

$>$ From experimental analysis, depth of etching is directly proportional temperature and time of etching.

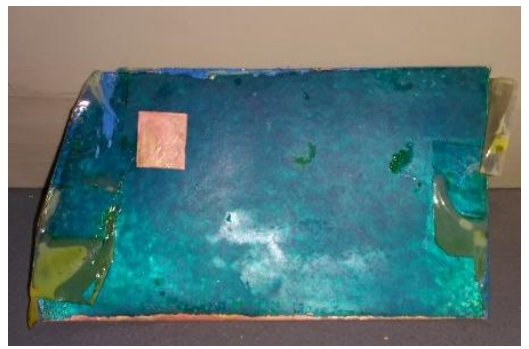

Fig.6 Etched component (2D)

The Etched component is displayed in Fig 6.

\section{CONCLUSION}

The present study investigates the depth of etching by different operating conditions. As per this study, following conclusions are made. In this study, the effects of process parameters were kept varying and the machining is studied by using different time period for etching.

1. Depth of etching is proportional to temperature of etching material.

2. Highest depth of etching is achieved for $42^{\circ} \mathrm{Cand}$ 8 min etching time.

3. Lowest depth of etching is achieved at $34^{\circ} \mathrm{C}$ and 2 min etching time.

\section{REFERENCES}

[1] S.S.Wangikar, P. P. Patowari, and R. D. Misra, "Effect of process parameters and optimization for photochemical machining of brass and German silver" Materials and Manufacturing Processes, vol. 32 no. 15, pp.1747-1755, 2017.

[2] S.S. Wangikar, P. P. Patowari, and R. D. Misra, "Parametric optimization for photochemical machining of copper using overall evaluation criteria" Materials Today: Proceedings, vol. 5, no. 2, pp. 4736-4742, 2018.

[3] Andrew R. Barron "Composition and PhotochemicalMechanisms of Photoresist*

[4] N. D. Misal, A. R. Saraf, and M. Sadaiah, "Experimental investigation of surface topography in photo chemical machining of Inconel 718”, Materials and Manufacturing Processes, vol. 32, no. 15 , pp.1756-1763, 2017.

[5] A. R. Saraf, N. D. Misal, and M. Sadaiah, "Mathematical modeling and optimization of photo chemical machining". In Advanced Materials Research, Vol. 548, pp. 617-622, 2012.

[6] Barron, A. R. (2009). Composition and Photochemical Mechanisms of Photoresists. Creative Commons, 1, 1-7.

[7] Allen, David M., Almond, Heather J.A, 2004, "Characterization of aqueous ferric chloride etchants used in industrial photochemical machining", Journal of Materials Processing Technology, 149, 238-245.

[8] Allen, D. M. (2004). Photochemical machining: from 'manufacturing's best kept secret'to a $\$ 6$ billion per annum, rapid manufacturing process. CIRP Annals-Manufacturing Technology, 53(2), 559-572.

[9] S. S. Wangikar, P. P. Patowari, R. D. Misra, and N. D. Misal, "Photochemical Machining: A Less Explored Non-Conventional Machining Process", In Non-Conventional Machining in Modern Manufacturing Systems, pp. 188-201, 2018.

[10] S. S. Wangikar, P. P. Patowari, and R. D. Misra, "Parametric Optimization for Photochemical Machining of Copper Using Grey Relational Method”, In Techno-Societal 2016, International Conference on Advanced Technologies for Societal Application, pp. 933-943, 2016. 
Etching Depthvariation of Brass Material for Different Operating Conditions

[11] Das, S. S., Tilekar, S. D., Wangikar, S. S., \& Patowari, P. K. (2017). Numerical and experimental study of passive fluids mixing in micro-channels of different configurations. Microsystem Technologies, 23(12), 5977-5988.

[12] Wangikar, S. S., Patowari, P. K., \& Misra, R. D. (2018) Numerical and experimental investigations on the performance of a serpentine microchannel with semicircular obstacles. Microsystem Technologies, 24:3307, 1-14. 